\title{
DIE POSISIE VAN DIE HELPER IN DIE SENDING
}

\section{Aktualiteit van die vraagstuk}

Gedurende die aanvangsjare van die sending het die helper 'n onmisbare funksie vervul. Hulle het die onherbergsame binnelande geken, waardevolle kontakpunte vir die sendelinge geopen en hulle mense geestelik help voorlig en voorberei. ${ }^{1}$

Tereg kan gesê word: ,the village catechist ${ }^{2}$ with his slender qualifications and very modest pay, is the real hero of the Christian situation in Africa". ${ }^{3}$

Dit is egter helaas so dat die helper gaandeweg in die sending oor die wêreld heen 'n uitgediende figuur geword het. Sundkler bepaal bv.: "So far as Buganda is concerned, the age of the catechists is over".4

Die redes hiervoor is die volgende:

1.1. Dit is 'n te duur uitgawe op die lang duur. Die ou kerk kan onmoontlik nie met die volle $\mathrm{krag}$ van 'n leërskare betaalde kragte volhou nie. Wat meer is, die jong kerk kan ewe onmoontlik die finansiële vrag hieraan verbonde, oorneem. Gevolglik bly die jong kerk finansieel leun op die sending en bly die helper die simbool van finansiële onderhorigheid. ${ }^{5}$

1.2. Die voortdurende onderhouding van die helper d.m.v. die geld van die ou kerk maak van hom "to some extent the object of suspision". ${ }^{6}$ Ons besef dit nie so geredelik nie dat dit ernstige wantroue ten aansien van die bedoelinge wek. ${ }^{7}$

1.3. 'n Verdere rede is dat die helpers nie altyd die geleerdste en bes toegeruste persone vir die taak is nie. In die ontwikkelende gemeenskappe waarbinne die jong kerke groei, beskik hulle nie altyd oor die parate bevoegdheid om op gelyke vlak te beweeg en die kerk te verteenwoordig nie.

1.4. Die belangrikste rede is egter dat die helper binne die raamwerk van die beleid van die selfstandigheidsbeweging van die jong kerk nie meer inpas nie.

Vroeër was die sendeling die enigste persoon wat beslissings neem en wie se aandag aan alle sake gewy is.

Huidig is dit anders: ,the missionary no longer sits on his congregations like a hen on her chickens". ${ }^{8}$ Hy bemoei hom nie met alles nie. Sy taak is hoofsaaklik preek en sakramente bedien.

Waar die sendeling aanwesig bly met sy helpers, sien die helpers en die gemeente dit nie ter bevordering van hulle selfstandigheid nie. Inteendeel, hoe formeel en prinsipieel die verandering ook al ingeklee is, in praktyk is dit nog maar vir hulle die ou situasie. Die sendeling is in hulle oë steeds die regeerder en die helpers die assistente. ${ }^{9}$

Hulle beskou dit so dat die helper toegelaat word om te preek maar nie om sakramente te bedien nie en derhalwe ondergeskik is aan die sendeling.

Dat die helper ooit 'n sterk posisie sal verower in die oë van die gemeente is nie te voorsien nie. Sy ondergeskiktheid moet lei tot 
die aftakelinge van sy gesag. Uit hierdie oogpunt besien, is die helper dus die slagoffer van die selfstandigheidsbesef van die jong kerk.

In ons eie sending is dit wesenlik die probleem waarom dit gaan. Die helper het nie meer, soos in die goeie ou dae, net te doen met die sendeling teenoor wie hy verantwoording verskuldig is nie. Hy het nou te doen met die sendeling, en die volle kerkraad van die jong kerk.

Gewoonlik is hy ouderling in een van die jong kerke. Maar die verhouding bly krap omdat: 1) die kerkraad hom nie heelhartig sien as een van hulle nie; 2) hy meesal in diens van die sendingkommissie en sendende kerk is en homself beskou as slegs verantwoordelik aan diegene in wie se diens hy staan; 3 ) hy nie so goed toegerus is vir sy taak nie.

\section{Die Bybelse fundering vir die ,helpers"}

Die woord "helper" is een van die verskeie terme wat gebruik word t.o.v. die talle persone wat in meerdere of mindere mate by die werk van die apostels betrek was.

Johannes Markus word in Hand. 13 : 5 die helper van Paulus en Barnabas genoem. Hy vergesel hulle nl. na Ciprus waar hy goed bekend was. Daarby is hy ' $n$ neef van Barnabas sodat die verwantskap waarskynlik ook 'n faktor by sy keuse as helper was. ${ }^{10}$

Later is Silas deur Paulus saamgeneem. Sy posisie was egter heel anders. Hy is, soos Barnabas, self apostel (Hand. 14 : 4 vv., 1 Thess. $2: 6$ ).

Die Nuwe Testament bied ' $n$ haas onvoorsienbare skare van helpers in die sin van persone wat op allerlei wyse aan die apostels hulp verleen het. Die groetelyste in die sendbriewe is ' $n$ aanduiding van enkele van hulle. ${ }^{11}$

Wie en wat was hierdie mense?

Dit moet gesien word teen die agtergrond van die begrippe „amp" en „charisma” t.o.v. die Nieu-Testamentiese kerk.

Die charisma of gawes is die kompleks van geestesgawes wat aan die gelowiges gegee is en wat deur die Heilige Gees gebruik word tot opbou van die kerk.

Die gawes fungeer egter in die kerk as diens (amp) terwyl dit „in dit dienstkarakter ook alleen zijn bestemming en zijn criterium vind ..." 18

Amp en gawe is nie so duidelik van mekaar te onderskei nie omdat die grens besonder vloeiend is. ${ }^{14}$

Feit is egter dat die kerk nie net charismaties bestaan nie maar ook institusioneel. Die charisma neig tot die institusionele. Dit beteken dat die gemeente nie net tydelik en t.o.v. bepaalde sake nie, maar t.o.v. sy ganse bestaan 'n „vaste instrumentering" ontvang. ${ }^{15}$ Charisma en amp moet dus nie teen mekaar afgespeel word of teenoor mekaar geplaas word nie.

Die amp dien die gawe terwyl die gawe gestel is onder leiding van die amp. ${ }^{10}$ Ridderbos kom tot die konklusie dat die amp ook 
self ' $n$ charisma is. ${ }^{17}$ Aldus is daar nie minder nie as 18 ampte en gawes te onderskei t.o.v. die struktuur van die N.T. kerk.18

Die vraag is nou: hoe loop die lyn vanaf hierdie ampte en gawes na die sendingsituasie? Wat van besondere toepassing is, is die apostels en die Evangeliste.

Wat die apostels betref verwerp ons die apostoliese suksessie maar handhaaf die apostolisiteit van die kerk. Dit impliseer apostolisiteit t.o.v. meerdere ampswerk, selfs die diakonaat.

Dit is dus oorvereenvoudiging om 'n enkele lyn te trek vanaf die apostels na bv. die sendeling, hoe sterk die ooreenkoms ook al is.

Hieruit vloei voort dat dit ook nie so eenvoudig is om 'n gelykteken te plaas tussen die evangelies van die Nuwe Testament en die helper van vandag nie, hoe sterk die analogie ook al is. Die apostels self is ook evangeliste in 'n sekere sin. Maar die evangelis is beslis die naaste aan die hedendaagse helper in die sending. ${ }^{19}$

Dit is nie so maklik om die inhoud van die woord "evangelis" te bepaal nie. Die woord kom net driemaal voor in die N.T. In Hand. 21 : 8 word Filippus, een van die sewe diakens, so genoem. In 2 Tim. $4: 5$ word Timotheus vermaan om die werk van 'n evangelis te doen.

In Ef. 4 : 11 word die evangeliste genoem saam met die ander dienste. Die evangeliste was vermoedelik in die begin genoem al die gemeentelede wat, sonder om apostel te wees, aktief ingeskakel was by die verkondiging van die evangelie. ${ }^{20}$

Hulle was, nader bepaal, die groep manne wat ,in voortdurend contact met die apostelen staan ... die door hen tot allerlei, vaak zeer zelfstandig werk worden gebruikt en evenals zij voortdurend voor de heidenzending op reis zijn"..21

Hulle is dienaars van die gemeente en van die apostels en staan dus tussen die apostels en profete en die herders en leraars. Hulle werk is die volgende: ${ }^{22}$ Verkondiging van die Woord, vermaning van en opsig oor die leer en lewe van gemeente en ampsdraers, dwaalleer weerlê en bestraf, reël van die werk van die weduwees, gemeentes aanmaan tot 'n heilige lewenswandel en die leiding neem by die aanstelling van ampsdraers. Wat nie genoem word nie is dat hulle sakramente bedien het.

Ridderbos meen egter: „stellig zullen de evangelisten zich niet beperkt hebben tot de verkondiging van het evangelie, maar ook gedoopt en aanwijzingen gegeven hebben voor de stichting der inrichting der gemeente".2s

Hulle eintlike werk was egter die prediking van die evangelie. Nader besien kan t.o.v. hulle diens en gawe die volgende bepaal word t.o.v. hulle ampswerk:

a) „Ook hier valt van een bepaald ampt, in de zin van een geordende aanstelling met stelligheid te spreken"..24 Tog is hulle werk in 'n sekere sin amptelik soos daaruit blyk vir Timotheus deur die ouderlinge hande opgelê is (1 Tim. $4: 14$ ). So ook was Eprafroditus (Filip. 2 : 25) eers afgevaardigde na Paulus. Daar is reisgeld aan hulle gegee. Hulle is aan die kerk wat hulle stuur gebonde: „in zekere zin zijn dus deze menschen niet alleen uit de gemeente gere- 
cruteerd, maar blijven zij ook namens de gemeente arbeiden"..25

b) Hulle is dus dienaars van sowel die gemeente as die apostels. Die apostels oefen groot invloed op hulle uit, veral omdat hulle oor die algemeen jong mense is.

c) Hulle is nie soseer verbonde aan of gestuur deur een bepaalde kerk nie maar die kerk in die algemeen en werk ook meer t.o.v. die kerk in die algemeen.

d) Hulle werk dra ' $n$ min of meer selfstandige karakter.

e) Hulle werk is voltooiing en afronding van wat deur die apostels gedoen is en bestaan uit ' $n$ ryke verskeidenheid - vanaf verskaf van losies tot bediening van die Woord.

f) Die hartlike verhouding wat tussen hulle en die apostel Paulus bestaan, word weerspieël in die volgende benoemingsname:20 jukgenoot, reisgenoot, medewerker, medestryder, medeslaaf, medegevangene, waaruit ook veral sy vaderlike gesag meer as enige juridiese outoriteit spreek.

Aldus het hulle t.o.v. die uitbouing van die Nieu-Testamentiese kerk ' $n$ belangrike rol vervul, en het instrumenteel 'n baie belangrike funksie vervul by die ontstaan en groei van die Christelike kerk. Hulle het egter saam met die apostels van die kerklike toneel af verdwyn.

\section{Die voorgestelde nuwe struktuur}

Die antwoord op hoe die nuwe situasie t.o.v. die helper en helpers sonder vergoeding van buite hanteer moet word, bied verskillende antwoorde op die sendingvelde van die wêreld.

Die kerk in Korea was van die begin af finansieel selfstandig: ,,all the salaries of Korean workers carrying on active evangelistic word among their own people, were raised by the Korean Church".27

Behalwe vir spesiale programme, is die salaris van helpers nie anders as deur die lidmate self bekostig nie. "In this way, from the start, the burden of the evangelistic work among the Korean people was placed squarely upon the infant church, which responded nobly and magnificently". ${ }^{28}$ So ook is die Nevius metode in China gevolg waarvolgens die salarisse van sendelinge en ongeordende werkers self betaal is. ${ }^{2 \theta}$

Die ander weg word ook gevolg, naamlik om die evangeliste nie te vervang nie. So bv. die Roomse Kerk in Buganda, ${ }^{30}$ wat meer gebruik maak van jong predikante. So ook die Anglikaanse kerk wat ten minste 'n beter gehalte helper in die veld stoot.s1

Twee oplossings t.o.v. hierdie prohleem word in die sending. literatuur en -praktyk aan die hand gedoen.

3.1. Die instelling van ' $n$ lekeamp in die kerk. Daarmee word bedoel dat van die gewone lidmate nie net die Woord mag bedien nie, maar ook die sakramente moet bedien. Die motivering hiertoe kan soos volg saamgevat word:

3.1.1. Die predikante is so min en die plekke waar nagmaal be- 
dien moet word, so baie dat dit 'n onuitvoerbare program word vir die sendeling. Slegs met ' $n$ uiterste poging kan die predikant eenmaal in die twee of drie maande by al die plekke besoek aflê. Predikante moet tot drie nagmaalsbedieninge op 'n Sondag behartig en aansienlike afstande tussen die punte aflê. Dit maak van die nagmaal 'n gejaagde geleentheid en die rus en vredigheid ontbreek. ${ }^{82}$

3.1.2. 'n Oorskatting van die nagmaal. Die jong Christene kan maklik die sakramentsbediening hoër en belangriker ag as die Woordbediening en dit selfs magies bejeën. Stephen Neill sien dit so: „it is much more likely that the sacrament will come to be regarded as an ornament on the periphery of the Church's life, a certificate of merit for those who are exceptionally regular in church attendance". ${ }^{83}$

Kraemer besien dit aldus: ,the danger of romanticism, in this case sacramental romanticism. We place the Sacraments in an atmosphere of inaccessible holiness". ${ }^{34}$ Dus op sterkte van hierdie motivering, so word betoog behoort die instelling van 'n leke-apostolaat oorweeg te word. Veral Stephen Neill is 'n ondubbelsinnige eksponent van hierdie gedagte.

Die vraag is, aldus Neill, waarom van die sg. lekewerkers nie Woord en sakramente kan bedien nie, ,.without beina ohlired to give up the ordinary avocation by which they earn their daily bread".so

Met ander woorde dit moet moontlik wees om gewone boere, handelaars of juriste te orden om die sakramente te bedien. Van hulle openbaar soms meer inisiatief en ondernemingsgees as die betaalde helpers en geestelikes. ${ }^{3 \theta}$

Dit moet 'n nuwe rigting in die kerk aandui insover dit vrywillige arbeid sal inbou in die struktuur van die gemeente. Dit sal nie die huidige vaste predikant oortollig maak nie en ook nie die lidmate in „lekediens" predikante maak nie. Dit sal egter die predikant in ' $n$ ander situasie in die gemeente te staan laat kom. Dit sal eerstens die predikant voor die uitdaging stel om die vrywillige werk ten beste te kontroleer en te organiseer.

Tweedens sal 'n sekere weerstand vanweë die gemeente oorbrug moet word omdat daar andersyds lidmate is wat'n hoog aangeskrewe persoon sal minag as hy eenvoudig kategetewerk doen. Andersyds is daar diegene wat sal dink dat hy eer daarin soek om vir hom status deur middel van die gemeente te verwerf. ${ }^{37}$

Dit sal egter nie, so word gestel, die getal of kwaliteit van die voltydse en bepaalde dienaars beinvloed nie.

Neill sê: „the development of new ministries could be only a supplement to and not a substitute for, existing ministries". ${ }^{38}$ Wat meer is, dit sal ,impose new duties and new demands on the whole time minister". Wat meer is, die deeltydse predikant "will need careful quidance and help in all that he undertakes". ${ }^{80}$

So word hy die hoof van die groep werkers en is hy in die letterlike sin van die woord pastor pastorum. Nader gepresiseer beteken dit: „It will be his task to do as little as possible himself, and to attempt to do everything through those collegues into whom 
it is his task to breathe something of his own spirit".40

Biskop Vaughan sluit hom hierby aan deur ook te praat van die funksies wat die "laity" moet oorneem maar daarby te konstateer dat "the clergy as a special order in the church have a strategic role to play in the perfecting of the samits". ${ }^{11}$

Die Presbiteriaanse Kerk in die Kameroen het o.a. reeds in die rigting beweeg deur in die K.O. te bepaal: „Zum nicht - ordinierten Alufgehören alle andern Glieder der Kirche, die sich an 'ror Erbaung des Leibes und der Verkündiging des Evangeliums in die Welt beteiligen". ${ }^{22}$ Volgens hierdie Kerkorde kan die nie-geordende ampsdraer dan nagmaal bedien maar hy mag nie doop nie.

3.2. Die helper-evangelis moet ampsdraer wees. Hierdie gedagte vind sterk steun by sendingskrywers en sendelinge. ${ }^{48}$ Die argumente wat ten gunste hiervan aangevoer word, is die volgende:

3.2.1. Die Gereformeerde beskouing bepaal dat Woordverkondiging en sakramentsbediening gelykwaardig is sodat daar geen beswaar kan wees dat 'n helper ook die sakramente bedien nie. Dus: "of ons moet die helper verbied om nog langer te preek, of ons moet hom ook toestemming gee om die sakramente te bedien".4t Ter verdere motivering word gesê dat die onderskeiding van amptelike bediening en 'n stigtelike woord nie opgaan nie en dat daar geen wesenlike verskil is tussen die prediking van 'n predikant of helper of proponent of ouderling nie omdat die gesag van die prediker nie by die persoon lê in die Roomse sin van die woord nie maar in die Woord self.

3.2.2. Die weerhouding van die helper van die reg om sakramente te bedien werk sakramentalisme in die hand. "Die gevolg is", sê Vonkeman, ,dat die Bantoekerk hopeloos ly aan sakramentsoor-skatting en 'n Woord-onderskatting. ${ }^{45}$

3.2.3. Dit kan die weg open tot 'n vermagisering van die nagmaal deur die Bantoechristene. ${ }^{46}$

3.2.4. Die Nuwe Testament leer dat die helper 'n amp besit te wete die amp van evangelis, ${ }^{47}$ bygevolg waarvan die helper in sy amp bevestig kan word.

\section{4. 'n Evaluasie van die bostaande}

Ad. 1 (insake leke-ampsdraers in plaas van helpers). Dat die amp van die gelowige veelal misken en in onbruik geraak het en nie genoegsaam funksioneer nie, allermins op die sendingveld, sal seker deur niemand betwis wil word nie.

In die besef dat die sending oorgaan en oorgegaan het in die hande van die jong kerk self, en die gevolglike moeilike posisie van helpers, sal die jong kerk self ook hierin 'n nuwe weg moet vind.

Langs die weg van 'n vollediger beoefening van die amp van die gelowige sal 'n groot deel van die las wat deur die helpers gedra word, oorgeneem kan word. Dit kan soos volg uitgedruk word: 
,,alleen indien er in die kerken groeit een vurige overtuiging dat elke gewone Christen zijn voeten moet schoeien met de bereidheid van het evangelie van Christus, en dat elke gelovige dag aan dag de gelegenheden die God hem geeft, zich te nutte maken moet, alleen indien dat gebeurt, is er nog veel te hopen en te verwachten"..7

Daarbenewens sal die beter funksionering van die amp van ouderling en die georganiseerde en doelgerigte opleiding en bekwaammaking van die ouderlinge 'n ewe belangrike vervanging van die dienste wat tans deur die helpers verrig word, tot gevolg he.

Die gedagte van die sg. "leke"-ampsdraer vind geen steun in die Skrif nie. Nêrens word in die Nuwe Testament nie-amptelik gewerk nie. Wat meer is, die aksent wat in die moderne teologie gelê word op die sg. "leek" sit vas aan die hele idee van 'n funksionele ekklesiologie waarin die nadruk eensydig val op die sending van die kerk. ${ }^{48}$ Hierdie kerkbegrip wil wegkom van die begrip van 'n kerk wat soos 'n kudde versorg moet word. Die kerk is dan nie meer 'n arbeidsveld vir die ampte nie, maar 'n arbeidsmag wat 'n roeping in die wêreld het. Die kerk moet nie iets vir homself as kerk wil doen nie, maar in dienskneggestalte die voorbeeld gee van ultruisties vir ander leef.

Bygevolg moet die kerk hom hoofsaaklik besig hou met die aardse node, verdrukking, onreg, lyde van mense ens.

Dan „wanneer de kerk nu zo helemaal naar buiten gekeerd is en zich vooral met het aardse heil inlaat, verschrompelt de grond onder de voeten van de traditionele amptsdrager, die toch zeker ook herder geweest is van een kudde die zelf wat nodig had en een drager was van een Woord van heil ook voor de mensen van de kerk".48

Die idee van leke ,ampsdraers" moet dus eers ontwar word uit die ekklesiologiese denke wat die kerk tot sosiale instelling devalueer.

As Vonkeman sê: „Die Skrif spreek baie minder ,amptelik' oor die ampte as wat ons doen" en "mens kry die stellige indruk dat in die jong gemeente van die Nuwe Testament die deur die Here gegewe charismata onmiddellik ingeskakel is in die opbou van die gemeente", ${ }^{\text {so }}$ ontbreek alle Nieu-Testamentiese fundering vir so 'n bewering.

Ad. 2 (die helpers as ampsdraers). Dit is waar dat die helpers soms maar swak toegerus is. Dit is dus belangrik dat, insover van helpers gebruik gemaak sal word, die mees bekwame manne daartoe in diens geneem sal word. ${ }^{11}$ Dit is ewe waar dat by die groeiende kerk die predikant 'n baie druk program het.

Die antwoord hierop is: meer predikante!

1. Dit is te simplisties gestel om te se dat die helper alles moet doen of niks. Iemand sal 'n stigtelike woord spreek in die kerk, die huisvader sal huisgodsdiens hou, amptelik, die ouderling sal 'n leesdiens hou, maar dit verg nie dat hulle ook sakramente sal bedien nie. Die diens van die sakramente is nie hoër of waardiger as die van die Woord nie maar staan tog midde in 'n intiemer samekoms van 
die gelowige wat daardie samekoms dan nie kwalitatief anders maak nie, maar tog op 'n ander vlak stel.

2. Dat die huidige stand van sake sakramentalisme in die hand werk, hoef nie te wees nie. Die gemeente weet maar te goed dat die bediening van die Woord in die sending dikwels in die vorm van 'n stigtelike woord kom en wil graag as gemeente saamkom om die nagmaal te gebruik soos deur die predikant bedien sonder dat die helper in status degradeer word. Almal weet mos, die helper self die beste van almal, dat hy nie 'n predikant is nie. As sakramentalisme 'n gevaar vir die gemeente is, sal dit op 'n ander manier bekamp moet word as om van 'n helper sakramentsbedienaar te wil maak.

3. Die Bantoelewe en Bantoe kerklike lewe is so vol neigings tot magisme, en daar is soveel voor die hand liggender geleentheid om magisties te wees in die Bantoe kerklike lewe dat die kans dat die blote feit dat ' $n$ helper nie nagmaal bedien nie magisme in die hand sal werk van baie ondergeskikte betekenis is.

4. As die helper (evangelis) 'n amp moet beklee, waarom nie al veertien die ander Nieu-Testamentiese ampte en gawes terugbring in die kerk nie? Apostels? Profete? Glossolalie? ens.

\section{Konklusie}

Opsommend en afsluitend wil ons bepaal:

1. As daar een saak bo die diskussie uitstyg, is dit die belangrikheid van die opleiding en beskikbaarstelling van predikante. Dit verdien die eerste en vernaamste aandag.

2. Ons moet versigtig wees vir die neiging om maar op die gees af te wil reël en sendingwerk doen sonder behoorlike kerkregtelike verantwoording en fundering. Raaflaub stel dit so: „wo aber Kirche Jesu Christi entsteht, ergibt sich die Notwendigkeit, ihr Handeln und ihr gottesdienstlichen Leben $\mathrm{zu}$ ordnen, ihr Bekenntnis nach auszen und gegen sektiererischen Tendenzen abzugrenzen, Richtlinien für das Amp festzulegen und für gute Leitung zu zorgen"..02 Miskien is daar 'n saak uit te maak dat daar 'n evangeliste amp moet wees. Miskien moet nog ander ampte bykom. Miskien moet dit verminder word. Maar dan moet daaroor behoorlik kerkordelik gehandel word en moet die institutêre liggaam van die jong kerk wat jurisdiksie het om daaroor te handel, so besluit.

3. Die helper is die verantwoordelikheid van die jong kerk self. 'n Groot aandeel tot die probleem rondom die helpers moet daaraan toegeskryf word dat die helper vir die rekening, finansieel, moreel en kerkregtelik, van die sendende kerk is. Die Nuwe Testament leer die verbondenheid van die helper aan die sendende kerk. Waar die sending nou deur die jong kerk vervang is, beteken dit mutatis mutandis dat hy die verantwoordelikheid word van die jong kerkraad. Die sendende kerk kan met die helper saamwerk, van hom verslag ontvang, aan hom opdragte gee ens., maar alles onder toesig van die jong kerkraad. Laasgenoemde moet hom ook besoldig, al is dit dat die sendende kerk hulle daarin sustenteer. 


\section{In die Skriflig}

4. Daar is ook steeds helpers uit die sendende kerk wat aan die sendende kerk verbonde bly. Hulle is prakties die lede van sendingkommissies e.a. wat aktief met die sending gemoeid is. Hulle is helpers of evangeliste in die suiwer Nieu-Testamentiese sin van die woord. Maar ook hulle werk sal nie bo-oor of langs die kerkraad van die jong kerk plaasvind nie. Soos die ander helpers sal hulle ook optree in volle medewerking met die jong kerkraad.

So sal sendende kerk en sendingkerk, ou en jong kerk meewerk tot die struktuur van die kerk wat sonder ampsdraers in teenspraak met homself sal wees.

Dr. I. J. van der Walt.

(Gelewer voor konferensie van sendelinge, Pretoria, November 1971).

1 Vgl. P. Beyerhaus: Die Selbstăndigkeit der Jungen Kirchen als Misstonarisches Problem, Wuppertal-Barmen, 1956, bl. 169.

2 Nie alle kategete is evangeliste nie.

3 I.M.C. Theol. Report, aangehaal deur B. Sundkler: The Christian Ministry in Africa, Londen, 1960, bl. 154.

4 A.w., bl. 138.

5 J. H. Bavinck: Inleiding in de Zendingswetenschap, Kampen, 1954, bl. $105,214$.

6 Stephen Neill: The Unfinished Task, Londen, 1958, bl. 217.

7 J. H. Bavinck: a.w., bl. 214.

8 H. Kraemer: From Missionfield to Independent Church", Londen, 1958, bl. 122.

9 A.w., bl. 123.

10 Johannes Markus het egter teruggekeer na Jerusalem en dus teleurgestel as helper. Daar was ook ernstige verskil tussen Paulus en Barnabas oor die verdere gebruikmaking van die dienste van Johannes Markus, vgl. Hand. 15.

11 Heinrich Kasting: Die Anfänge der Urchristlichen Mission, Munchen, 1969, bl. 107.

12 Vgl. P. A. E. Sillevis Smlt: De Organisatie van de Christelijke Kerk in den Apostolischen Tijd. Rotterdam, 1910, b. 118. H. N. Ridderbos: Paulus ontwerp van zijn Theologie, Kampen, 1966, bl. 494.

13 Idem, bl. 495.

14 L. Floor: In dieselfde spore, Potchefstroom, 1964, bl. 43.

15 H. Ridderbos: a.w., bl. 495.

16 Sillevis-Smit: a.w., bl. 123.

17 A.w., bl. 498.

18 Idem, bl. 490 v.v.

19 Vgl. Floor: a.w., bl. 43.

20 D. van Swigchem: Het Missionair Karakter van de Christelijke Gemeente volgens die Brieven van Paulus en Petrus, Kampen, 1958, bl. 152.

21 Idem, bl. 37.

22 Vgl. volledige weergawe by Floor: a.w., bl. 49.

23 A.w., bl. 508.

24 A.w., bl. 507. 
25 Van Swigchem: a.w., bl. 38. Floor oorbeklemtoon hulle verbondenheid aan die apostels ten koste van die band met die kerk.

26 Vgl. Floor: a.w., bl. 41.

27 T. S. Soltau: Missions at the Crossroads, Grand Rapids, 1959, bl. 95.

28 Idem, bl. 86.

29 Idem, bl. 53.

30 John V. Taylor: a.w., bl. 138.

31 Idem, bl. 139.

31 Stephen Neill: a.w., bl. 64 .

33 Idem, bl. 64.

34 H. Kraemer: From Missionsfield to Independent Church, Londen, 1958, bl. 124.

35 Stephen Neill: a.w., bl. 64.

36 John V. Taylor: a.w., bl. 140.

37 Idem, bl. 141.

38 Neill: a.w., p. 67.

39 Idem.

40 Idem.

41 B. N. Y. Vaughan: Structures for Renewal, Londen, 1967, bl. 63.

42 F. Raaflaub: Ordnung der Presbyterianischen Kirche in Mamerun, in Basileia, Stuttgart, 1958, bl. 288.

43 Vgl. L. Floor: a.w., bl. 49 e.v.

44 J. Vonkeman: Kritiese waardering van ons Gereformeerde Sendingbeleld, In die Skriflig, Jaargang 5, nr. 8, Pretoria, bl. 10.

45 L. Floor: a.w., bl. 50.

46 J. Vonkeman: a.w., bl. 10.

47 J. H. Bavinck: a.w., bl. 217.

48 Vgl. W. D. Jonker: Als een Riet in de Wind, Kampen, 1970, bl. 18.

49 Idem.

50 A.w., bl. 9.

51 Vgl. John V. Tayior: a.w., bl. 139.

52 A.w., bl. 292. 